\title{
Long non-coding RNA TRPM2-AS sponges microRNA-138-5p to activate epidermal growth factor receptor and PI3K/AKT signaling in non-small cell lung cancer
}

\author{
Dong Cui, Yu Feng, Kefeng Shi, Huimin Zhang, Rulin Qian \\ Department of Thoracic Surgery, Henan Provincial Chest Hospital, Zhengzhou, China \\ Contributions: (I) Conception and design: R Qian; (II) Administrative support: R Qian; (III) Provision of study materials or patients: D Cui, Y Feng, \\ K Shi, H Zhang; (IV) Collection and assembly of data: D Cui; (V) Data analysis and interpretation: D Cui, Y Feng; (VI) Manuscript writing: All \\ authors; (VII) Final approval of manuscript: All authors. \\ Correspondence to: Rulin Qian. No. 1 Weiwu Road, Zhengzhou 450008, China. Email: qianrulin2523@163.com.
}

Background: Long non-coding RNAs (lncRNAs) can play pivotal roles in tumor progression by acting as microRNA (miRNA) sponges. This study aimed to investigate the association of a novel lncRNA, TRPM2AS, with the miR-138-5p/EGFR axis in the development of non-small cell lung cancer (NSCLC).

Methods: Sixty NSCLC tissues and paired adjacent non-tumor tissues were analyzed. The relative expression levels of TRPM2-AS, miR138-5p, and epidermal growth factor receptor (EGFR) and the interactions between them were analyzed. The NSCLC cell lines NCI-H1299 and A549 were transfected with TRPM2-AS shRNA/pcDNA, and miR-138-5p mimics. Cell proliferation, migration, invasion, and apoptosis were examined in response to different transfection conditions. Dual-luciferase reporter assay was performed to identify the target interactions between TRPM2-AS, miR-138-5p, and EGFR. A549 cells stably transfected with shRNA were injected into BALB/c null nude mice to establish a tumor xenograft model.

Results: TRPM2-AS was up-regulated in NSCLC tumors and cell lines. Cell proliferation, migration, and invasion were inhibited in NSCLC cells treated with sh-TRPM2-AS, while apoptosis was induced. The targeting of TRPM2-AS by miR138-5p and miR138-5p by EGFR were validated with dual-luciferase reporter assay. TRPM2-AS was found to be negatively correlated with miR138-5p but positively correlated with EGFR. PI3K/AKT/mTOR was activated by pcDNA-EGFR but inactivated by miR-138-5p mimics. In the tumor xenograft mouse model, sh-TRPM2-AS suppressed tumor formation, reduced the expression of EGFR and Ki67, and promoted tumor cell apoptosis.

Conclusions: Our results suggested that TRPM2-AS can increase the levels of EGFR via sponging miR138-3p; this promoted NSCLC cell proliferation, migration, and invasion in vitro, and exacerbated tumors in vivo. These findings highlight TRPM2-AS/miR-138-5p as a potential target for reducing drug resistance in patients with NSCLC.

Keywords: Epidermal growth factor receptor (EGFR); miR-138; non-small cell lung cancer (NSCLC); TRPM2AS; phosphatidylinositol 3-kinase (PI3K)

Submitted Aug 17, 2020. Accepted for publication Oct 19, 2020.

doi: $10.21037 / \mathrm{atm}-20-6331$

View this article at: http://dx.doi.org/10.21037/atm-20-6331

(c) Annals of Translational Medicine. All rights reserved. 


\section{Introduction}

Lung cancer is one of the leading causes of cancer-related morbidity and mortality worldwide, accounting for about 2.1 million new cases and 1.8 million deaths annually $(1,2)$. In recent years, the overall survival of patients with non-small cell lung cancer (NSCLC) driven by epidermal growth factor receptor (EGFR) mutations has increased, owing to the development of EGFR tyrosine kinase inhibitors (EGFR-TKIs) (3). Unfortunately, resistance to chemotherapy drugs after surgery remains a significant factor influencing the prognosis of patients (4).

Aberrantly expressed long non-coding RNAs (lncRNAs) are widely understood to play vital psychological and pathological roles ubiquitously, including epigenetic regulation, genomic imprinting, and alternative splicing (5). Post-transcriptional regulatory processes of lncRNAs, such as sponging microRNA (miRNA) to promote downstream gene expression, have been implicated as important pathomechanisms for lung cancer (6). In recent years, IncRNA TRPM2-AS has been reported as an oncogene that sponges miRNA across different tumors $(6,7)$. TRPM2AS is an antisense lncRNA of TRPM2, which is located at chromosome $21 \mathrm{q} 22.3$ (8). Huang et al. reported that TRPM2-AS was up-regulated in NSCLC tissues compared with adjacent normal tissues, with its high expression indicative of poor survival (9). However, the role of TRPM2-AS in NCSLS has yet to be fully established.

MiR-138-5p has been described as a tumor-suppressor. For instance, Li et al. reported that circular RNA (circRNA) FOXO3 sponged miR-138-5p to promote the expression of nuclear factor of activated T cells 5 (NFAT5) and promoted the progress of glioblastoma (10). Gonzalez Dos Anjos et al. found that miR-138-5p was associated with higher disease-free survival in lung adenocarcinoma patients (11). Furthermore, miR-138-5p has also been shown to inhibit angiogenesis (12), drug resistance (13), epithelialmesenchymal transition and proliferation (14), with most of these processes directly or indirectly related to EGFR. In fact, Tang et al. predicted and verified EGFR to be a direct target of miR-138-5p in NSCLC (15). The potential therapeutic value of miR-138-5p in NSCLC is highlighted by its functional similarities with EGFR-TKIs, direct targeting of EGFR, and ability to reverse drug resistance.

In gastric cancer, HMGA1 was found to be up-regulated when TRPM2-AS was induced to sponge miR-138-5p (7). We hypothesized that TRPM2-AS is a potent sponge for miR-138-5p and promotes NSCLC progression by acting as a competing endogenous RNA for EGFR. This study aimed to investigate the targeting relationship and effects of TRPM2-AS, miR-138-5p, and EGFR in NSCLC progression, in vitro and in vivo. We present the following article in accordance with the ARRIVE reporting checklist (available at http://dx.doi.org/10.21037/atm-20-6331).

\section{Methods}

\section{Tissue samples}

The study was conducted in accordance with the Declaration of Helsinki (as revised in 2013). The study was approved by the Ethics Committee of the Henan Provincial Chest Hospital (No. 2018-53). Written informed consent was obtained from all participants. Sixty pairs of NSCLC tumor and adjacent normal tissues were harvested from NSCLC patients. After surgical resection, the NSCLC tissues were immediately stored in liquid nitrogen.

\section{Animal experiments}

All animal experiments were approved by Henan Provincial Chest Hospital (No. HHSXKYY-2019-019). The animal experiments in this study were performed in strict accordance with the Chinese National Guidelines (GB/T 35892-20181) and the Guide for the Care and Use of Laboratory Animals, 8th edition, published by the National Research Council (US) Committee. Four-week-old male BALB/c null nude mice were supplied by Vital River Laboratory Animal Technology Co. Ltd (Beijing, China). The mice were acclimated for 1 week before the experiment was commenced. The mice were housed in climatecontrolled room with a $12 \mathrm{~h} / 12 \mathrm{~h}$ light/dark cycle, with free access to food and water. A total of $1 \times 10^{6}$ A549 cells (stably transfected with shRNA-TRPM2-AS or shRNA-NC) in $100 \mu \mathrm{L}$ phosphate-buffered saline (PBS) were injected subcutaneously into the right flank of 5 randomly selected mice in each group. The tumor volume was measured every 5 days and calculated as: volume $=\left(\right.$ length $\times$ width $\left.^{2}\right) / 2$. On day 30 , the mice were anesthetized and sacrificed. The tumors were harvested for photographing and subsequent experiments.

\section{Cell culture and transfection}

Human NSCLC cell lines [human bronchial epithelial (HBE), National Cancer Institute (NCI)-H1299, A549, 
Table 1 The shRNAs and miRNA mimics used

\begin{tabular}{ll}
\hline Sequence name & \multicolumn{1}{c}{ Sequence (5'->3') or assay ID } \\
\hline $\begin{array}{l}\text { TRPM2-AS shRNA } \\
\text { scrambled }\end{array}$ & TTCTCCGAACGTGTCACGT \\
TRPM2-AS shRNA 1 & AGACCTATGAGGAGACATAAC \\
TRPM2-AS shRNA 2 & GGGAAGATGTCTCAGCAGACG \\
TRPM2-AS shRNA 3 & CGAACCTTCCCTAATAGAAAC \\
NC mimics/inhibitor & CAGUACUUUUGUGUAGUACAA \\
miR-138-5p mimics & AGCUGGUGUUGUGAAUCAGGCCG \\
\hline
\end{tabular}

Table 2 Primers used in PCR

\begin{tabular}{ll}
\hline Primer name & \multicolumn{1}{c}{ Sequence $\left(5^{\prime}->3^{\prime}\right)$} \\
\hline TRPM2-AS & F: CGTGACCAGGTTCAGACACA \\
R: TGGGCAGTTTGGTTCTGGTT & F: TGCAATGGGTTTGGCGTAGAAC \\
RiR-138-5p & F: GACACCTGCCCACCACTCAT \\
EGFR & R: CTCCCTGCCTCTGCTCACAT \\
& F: GGACCTGACCTGCCGTCTAG \\
GAPDH & R: TAGCCCAGGATGCCCTTGAG \\
& F: GCGCGTCGTGAAGCGTTC \\
U6 & R: GTGCAGGGTCCGAGGT
\end{tabular}

PCR, polymerase chain reaction; EGFR, epidermal growth factor receptor; GAPDH, glyceraldehyde 3-phosphate dehydrogenase.

NCI-H1650, NCI-H2228 and NCI-H292] were purchased from American Type Culture Collection (MA, USA). The cell lines were frozen and stored in our laboratory. The cells were cultured in Dulbecco's Modified Eagle Medium (DMEM, Gibco Company, Grand Island, NY, USA) containing $10 \%$ fetal bovine serum (FBS, HyClone Company, Logan, UT, USA) and 1\% PenicillinStreptomycin (Life Technologies, Paisley, UK) in an incubator with $5 \% \mathrm{CO}_{2}$ at $37^{\circ} \mathrm{C}$.

Short hairpin RNAs (shRNAs, sh-Scrambled, and 3 shRNAs for TRPM2-AS), miRNA mimics, and the corresponding controls (listed in Table 1, GenePharma, Shanghai, China) were transfected into NCI-H1299 and A549 cells with Lipofectamine 2000 (Invitrogen, Carlsbad, CA, USA) in line with the manufacturer's protocol. Stable cell lines were obtained by using $2 \mu \mathrm{g} / \mathrm{mL}$ puromycin
(Sigma-Aldrich, St-Louis, Missouri, USA) for 3 weeks to eliminate untransfected cells. TRPM2-AS 875 bp cDNA sequences were subcloned and amplified into the lentiviral expression vector (GenePharma).

\section{Quantitative real-time polymerase chain reaction (qRT-PCR)}

Total RNA was extracted from the cells and tissue samples using $1 \mathrm{ml}$ TRIzol reagent (Invitrogen) and underwent reverse transcription with a First Strand cDNA Synthesis Kit (Thermo Scientific, Hudson, NH, USA) following the manufacturer's instructions. The RNA level was quantified by qRT-PCR using a SYBR Premix ExTaq Reverse Transcription PCR kit (Takaka, Dalian, China). Glyceraldehyde 3-phosphate dehydrogenase (GAPDH) was used as an internal control for normalization. Table 2 lists the primers used.

\section{Colony formation assay}

After transfection, re-suspended NCI-H1299 and A549 cells were randomly seeded at a density of $1 \times 10^{3}$ cells/well in 6-well plates in $1 \mathrm{~mL}$ culture medium. For the transient transfection groups, cells were transfected with siRNA every 3 days using HiPerFect (Qiagen, Hombrechtikon, Switzerland). After incubation for 10 days, the cells were stained with $0.1 \%(\mathrm{~W} / \mathrm{V})$ crystal violet, and the colony formation rate was determined.

\section{Flow cytometry}

The proliferation of NCI-H1299 and A549 cells after transfection was analyzed by fluorescence-activated cellsorting (FACS) assay. For each assay, $100 \mu \mathrm{L}$ of cells at a density of $1 \times 10^{5}$ were incubated with Annexin V-FITC and propidium iodide (Tianjin Sungene Biotech Co. Ltd., Tianjin, China) in the dark at $4{ }^{\circ} \mathrm{C}$ for $10 \mathrm{~min}$. The cells were then washed twice with buffer and suspended in $500 \mu \mathrm{L}$ of buffer for analysis by flow cytometry.

\section{Transwell assay}

NCI-H1299 and A549 cell invasion was analyzed by Transwell assay. Briefly, Matrigel $(50 \mu \mathrm{g} / \mathrm{mL} \times 0.1 \mathrm{~mL}$, BD Biosciences, San Jose, CA, USA) was added to the upper chamber of the Transwell and incubated for $2 \mathrm{~h}$. 
Then, NCI-H1299 and A549 cells were seeded in the upper chamber in DMEM supplemented with $0.1 \%$ FBS. Meanwhile, the lower chamber was filled with DMEM supplemented with $10 \%$ FBS. After $24 \mathrm{~h}$ of incubation, the NCI-H1299 and A549 cells in the lower chamber were fixed with $95 \%$ ethanol, stained with hematoxylin, and the number of invading NCI-H1299 and A549 cells was counted.

\section{Wound-healing assay}

Wound-healing assay was carried out to evaluate the migration rate of transfected NCI-H1299 and A549 cells. Briefly, $5 \times 10^{6}$ cells/well were seeded in 6 -well plates and cultured overnight until the cells reached $90 \%$ confluence. Then, a sterile pipette tip was used to create straight scratches. The destroyed cells were gently rinsed off with PBS three times, and the plates were cultured for a further $24 \mathrm{~h}$. Cell migration was determined according to the average distance travelled by migrating cells, which was observed at 0 and $24 \mathrm{~h}$ with a digital camera (Leica DFC300FX) equipped with an inverted microscope.

\section{Western blot analysis}

Samples were lysed in lysis buffer (Beyotime, Shanghai, China). The loading buffer mixed samples $(25 \mu \mathrm{g}$ protein for each sample) were incubated in boiling water for $10 \mathrm{~min}$. The proteins were separated using sodium dodecyl sulphatepolyacrylamide gel electrophoresis (SDS-PAGE) and then transferred onto polyvinylidene fluoride (PVDF) membranes (Millipore, Massachusetts, USA). Next, the membranes were incubated with the related primary and secondary antibodies. The following antibodies were used: anti-Ki67 (ab92742), anti-EGFR (ab52894), anti-PI3K (ab70912), anti-p-PI3K (ab182651), anti-AKT (ab8805), anti-p-AKT (ab38449), anti-mTOR (ab32028), anti-p-mTOR (ab137133), antiGAPDH (ab181602), and Goat Anti-Rabbit (ab150077) (all purchased from Abcam, Cambridge, MA, USA). Finally, the proteins were detected using a ChemiDoc XRS imaging system (Bio-Rad, San Francisco, California, USA), with $\mathrm{GAPDH}$ as an endogenous reference.

\section{Immunohistochemical (IHC) and terminal deoxynucleotidyl transferase dUTP nick-end labeling staining}

To detect the expression of Ki67 and EGFR in the xenograft tumors, harvested tumor tissues were embedded in paraffin and cut into $4-\mu \mathrm{m}$-thick sections for IHC staining. The sections were rehydrated, and antigen retrieval was performed in citrate buffer for $3 \mathrm{~min}$ at $100{ }^{\circ} \mathrm{C}$. Then, the sections were incubated with primary antibodies against Ki67 and EGFR at $4{ }^{\circ} \mathrm{C}$ overnight. After incubation for a second time with goat anti-rabbit IgG at room temperature for $30 \mathrm{~min}$, the sections were washed thoroughly, stained with diaminobenzidine, and photographed by under a microscope. The expressions of Ki67 and EGFR were estimated with the level of integrated optical density. For the terminal deoxynucleotidyl transferase dUTP nick-end labeling (TUNEL) assay, rehydrated tumor tissue sections were stained using a TUNEL Apoptosis Detection kit (Millipore). Images of TUNEL-positive cells were taken with a fluorescence microscope. The images were analyzed with the Image Pro Plus software (Media Cybernetics, Bethesda, MD, USA) and presented as mean \pm standard error of the mean (SEM).

\section{Luciferase assay}

Luciferase reporter assay was carried out as previously described (6). Briefly, Lnc-TRPM2-AS, EGFR, or mutant EGFR were predicted as targets of miR-138-5p by RNA22HAS (https://cm.jefferson.edu/rna22/) and TargetScan V7.2 (http://www.targetscan.org/vert_72/), as shown in Table S1 and Figures S1,S2. The mutant 3'-UTR construct was made by introducing the mismatch mutation into the putative seed regions of EGFR and TRPM2-AS, respectively (Figures S3,S4). Next, the cDNA sequences for TRPM2 and EGFR (GenePharma) were subcloned into pGL3-basic luciferase reporter vectors (Promega, Madison, Wisconsin, USA). NCI-H1299 and A549 cells were seeded into 96-well plates and co-transfected with luc-TRPM2-wt/luc-TRPM2mut or luc-EGFR-wt/luc-EGFR-mut, and miR138-5p mimic/NC mimic using Lipofectamine 2000 (Invitrogen). At $48 \mathrm{~h}$ after transfection, a Dual-Luciferase Reporter Assay System (Promega) was used to measure luciferase activity according to the manufacturer's instructions. Relative luciferase activity was normalized to Renilla luciferase.

\section{Statistical analysis}

Graphpad Prism 6.0 (Graphpad Prism, San Diego, CA, USA) was used for statistical analysis. All in vitro tests were independently carried out by two different technicians at least 6 times. Data are shown as mean \pm standard deviation (SD). Characteristics of clinical samples were analyzed using 
Table 3 Correlation of TRPM2-AS expression and the clinicopathological characteristics of NSCLC patients

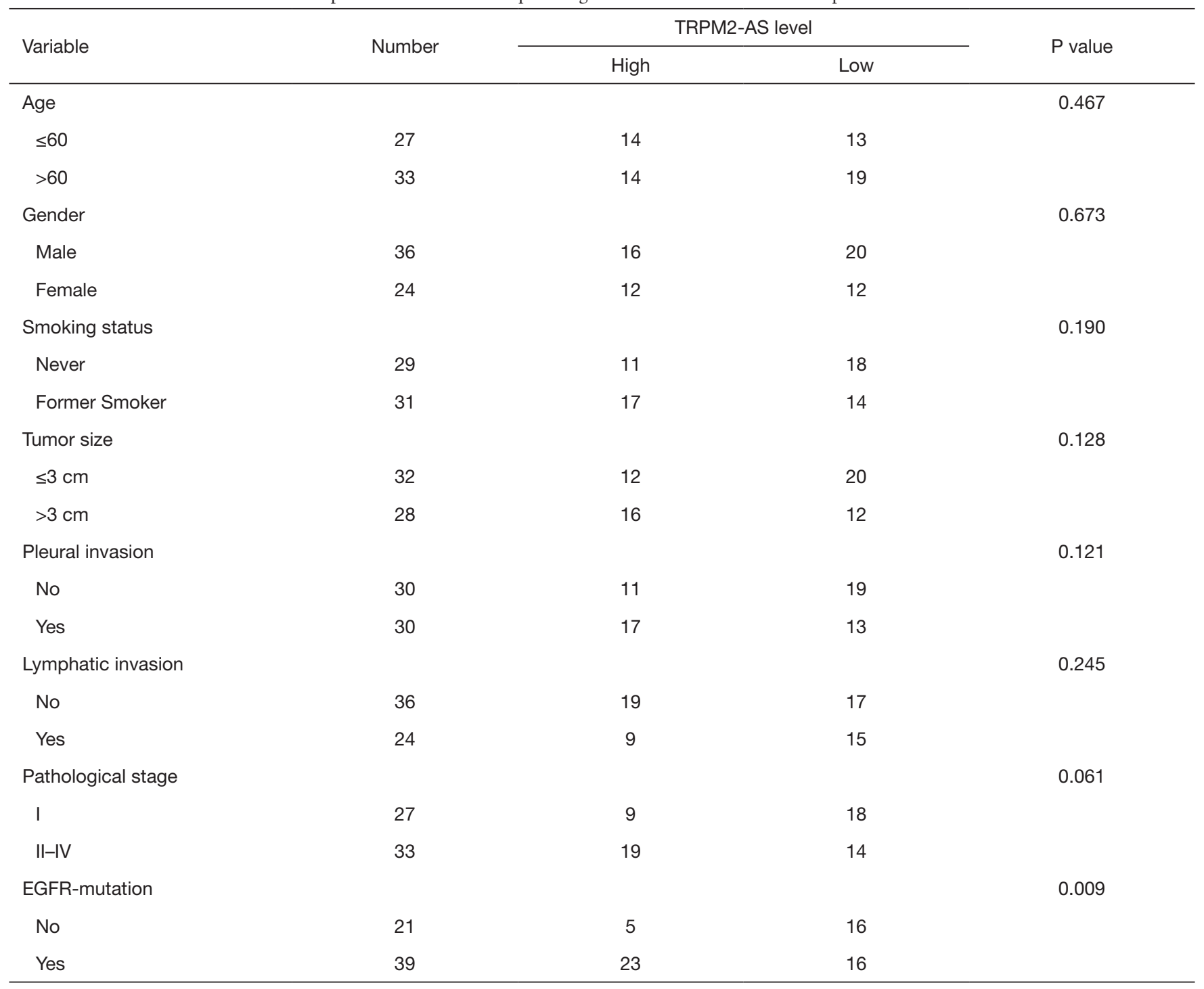

NSCLC, non-small cell lung cancer; EGFR, epidermal growth factor receptor.

Pearson's chi-squared test. Correlations between TRPM2AS, miR-138-5p, and EGFR were analyzed with Pearson's correlation. Other data was analyzed using Student's $t$-test or one-way analysis of variance (ANOVA). $\mathrm{P}<0.05$ was considered to indicate a statistically significant difference.

\section{Results}

\section{TRPM2-AS was elevated tumor tissues and promoted} tumor progression in NSCLC

The expression of IncRNA TRPM2-AS in 60 pairs of NSCLC tumor and adjacent tissues was evaluated by qRT-
PCR. The relationship between TRPM2-AS expression and the clinicopathological characteristics of NSCLC patients was evaluated. TRPM2-AS expression in tumors was significantly correlated with the presence of EGFR mutation (Table 3). Elevated levels of TRPM2-AS were observed in NSCLC tissues compared to the adjacent normal tissues (Figure 1A). TRPM2-AS was also higher in NSCLC cell lines, especially NCI-H1299 and A549 cells, than in human bronchial epithelioid (HBE) cells (Figure 1B).

Next, the effects of TRPM2-AS in NSCLC cell lines NCI-H1299 and A549 were explored. Three shRNAs (Table 1) for TRPM2-AS were transfected into both 

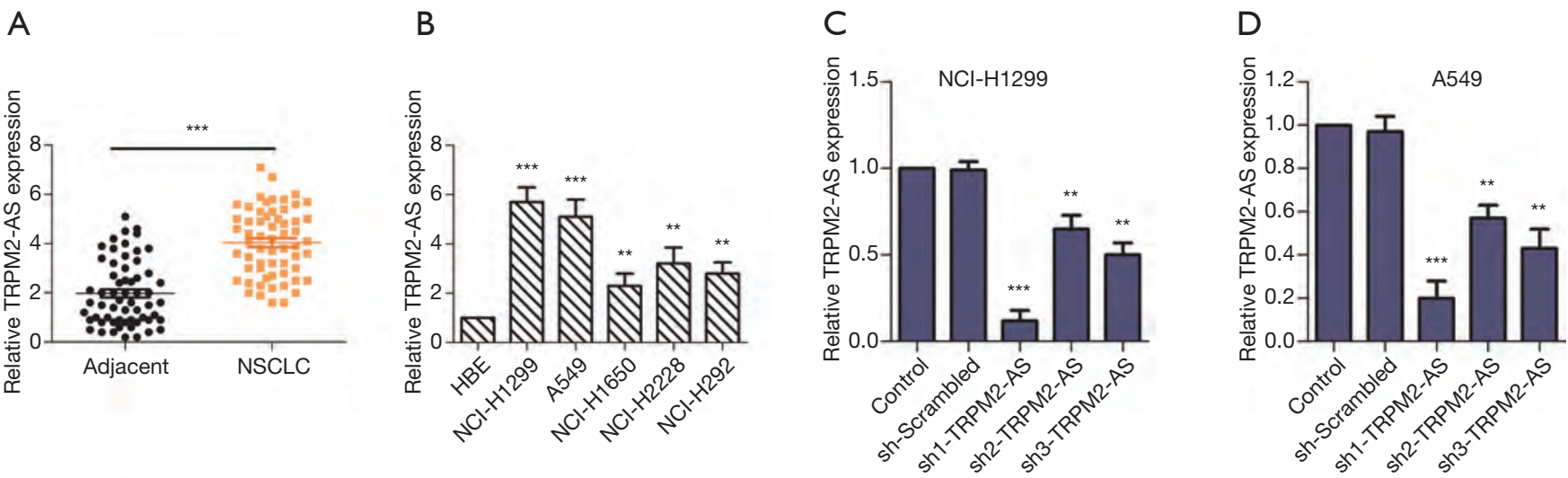

E

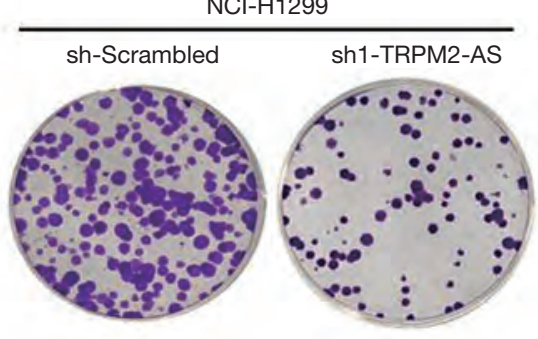

F

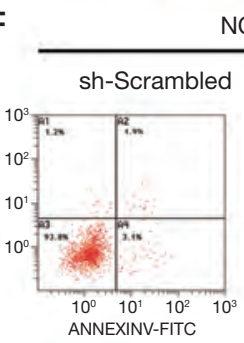

$\mathrm{NCl}-\mathrm{H} 1299$

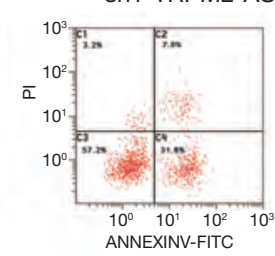

G
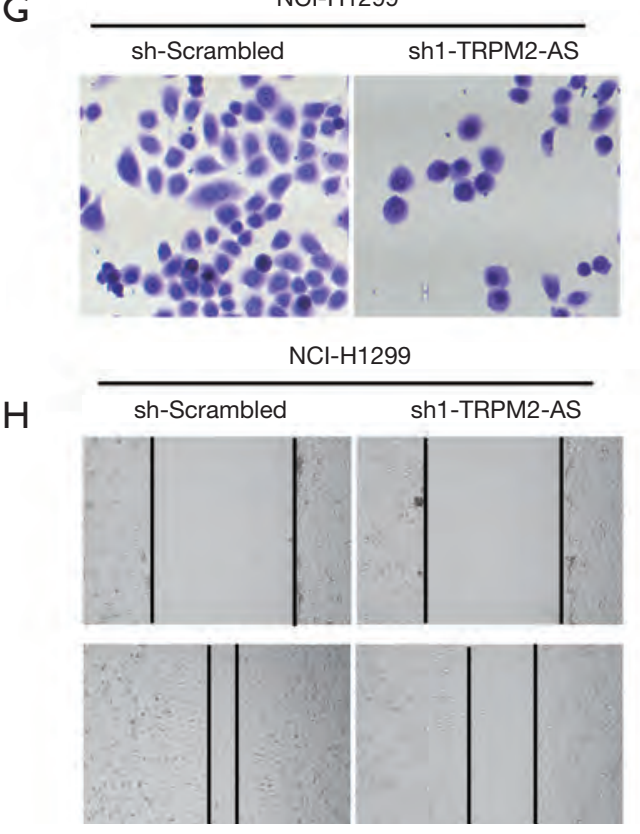

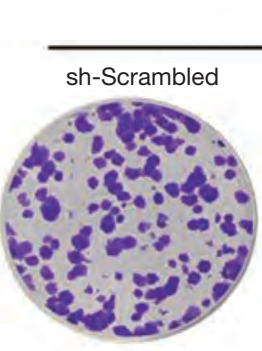

A549
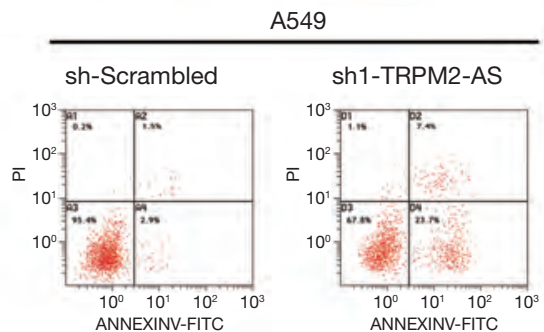

A549

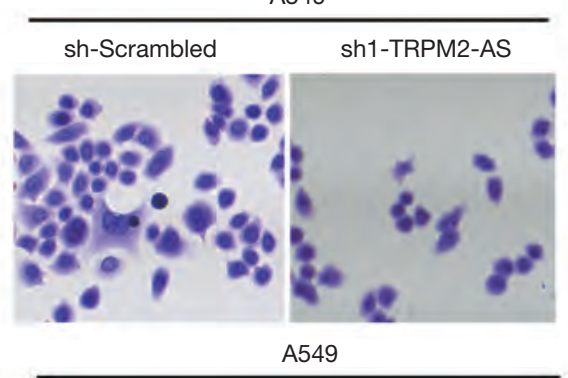

sh1-TRPM2-AS
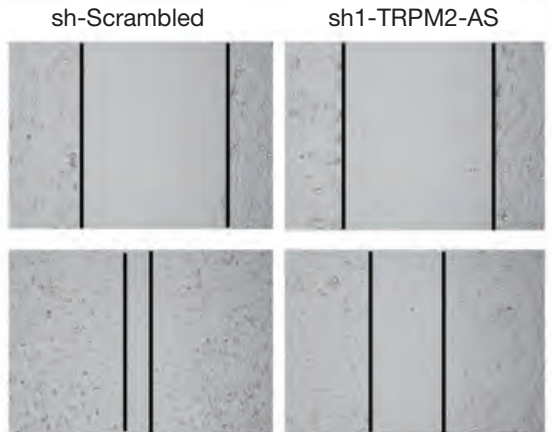
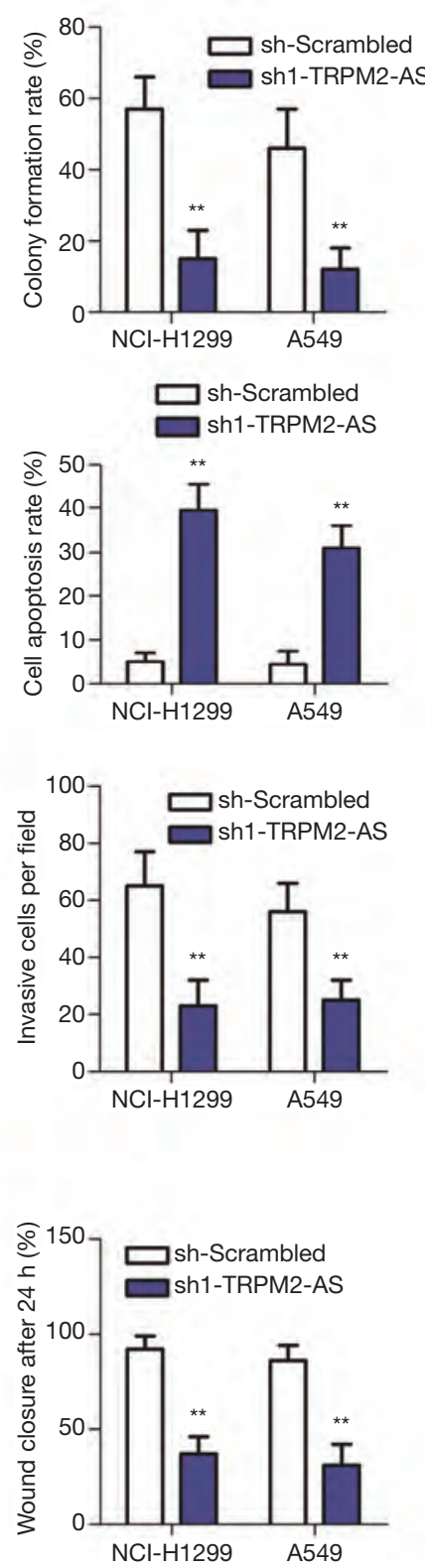

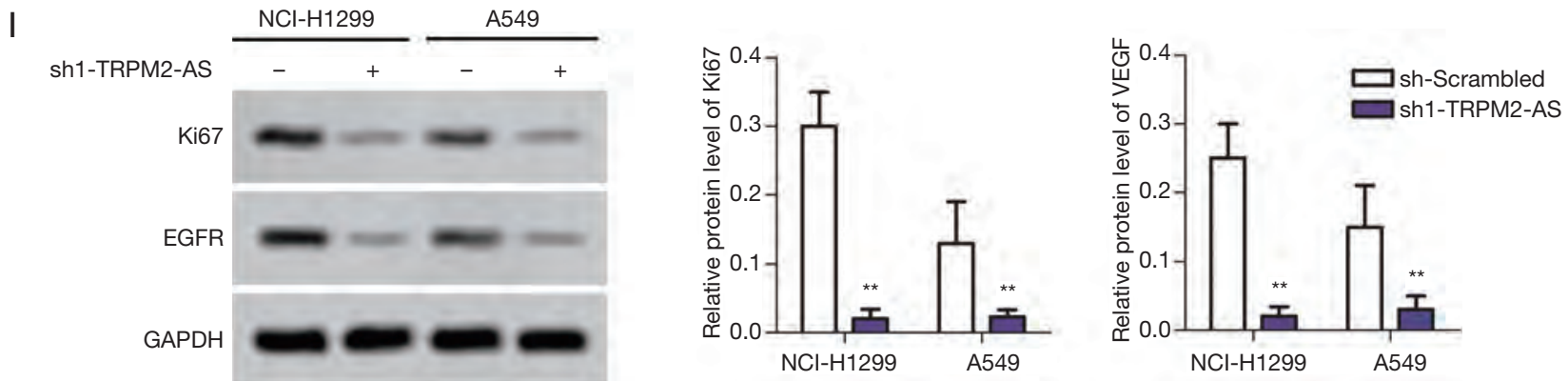

Figure 1 Expression profile and effects of TRPM2-AS in NSCLC. (A) TRPM2-AS expression in NSCLC and adjacent tissues from 60 patients was analyzed by paired $t$-test. (B) TRPM2-AS expression in normal HBE cells and several NSCLC cell lines. TRPM2-AS expression in NCI-H1299 (C) and A549 (D) cells transfected with the indicated shRNAs were tested with qRT-PCR. Colony formation (stained with crystal violet and directly photographed with a digital camera) (E), apoptosis (F), invasion (stained with crystal violet and observed under 400x scope) (G), and migration (H) in NCI-H1299 and A549 cells transfected with sh-TRPM2-AS were analyzed with colony formation assay, flow cytometry, Transwell assay, and wound-healing assay, respectively. (I) Protein expression in NCI-H1299 and A549 cells transfected with sh-TRPM2-As. Data are shown as mean $\pm \mathrm{SD}$. **, $\mathrm{P}<0.01$ versus control and ***, $\mathrm{P}<0.001$ versus control with $t$-test. NSCLC, non-small cell lung cancer; HBE, human bronchial epithelioid; qRT-PCR, quantitative real-time polymerase chain reaction. sh1TRPM2-As was also marked as sh-TRPM2-As.

cell lines. sh1-TRPM2-AS showed the most significant inhibition of TRPM2-AS in both NCI-H1299 (Figure 1C) and A549 (Figure 1D) cells, and it was used in later experiments and marked as sh-TRPM2-AS. The overall effects of sh-TRPM2-AS on NCI-H1299 and A549 cells were then investigated. Knock-down of TRPM2-AS significantly reduced colony formation (Figure $1 E$ ), induced apoptosis (Figure $1 F$ ), and inhibited invasion (Figure 1G) and migration (Figure 1H) in both cell lines. The expressions of Ki67 and EGFR protein were markedly reduced in NCI-H1299 and A549 cells transfected with sh-TRPM2AS (Figure 1I). These findings indicated that TRPM2 is highly expressed and promotes tumor progression in NSCLC, which is possibly related to EGFR.

\section{TRPM2-AS is targeted by miR-138-5p in NSCLC}

The targeting relationship between miR-138-5p and TRPM2-AS was then investigated. The expression of miR$138-5 \mathrm{p}$ was markedly lower in the NSCLC specimens than in the adjacent normal tissues (Figure $2 A$ ). Similarly, miR-138-5p expression was also decreased in the tested NSCLC cell lines, especially in A549 and NCI-H1299 cells (Figure 2B). Target prediction of TRPM2-AS/miR-1385p with RNA22-HAS revealed 20 potential miR-138-38 sponging sites in TRPM2-AS. NCI-H1299 and A549 cells co-transfected with Luc-TRPM2-AS-wt and miR-138$3 \mathrm{p}$ mimic showed significantly decreased luciferase activity compared to the mutant or NC mimic co-transfected controls (Figure $2 C$ and Figure $2 D$ respectively). The expression of miR-138-5p was elevated in NCI-H1299 and A549 cells treated with sh-TRPM2-AS (Figure 2E). TRPM2-AS was also overexpressed in NCI-H1299 and A549 cells (Figure 2F); consequently, the relative expression of miR-138-5p was significantly inhibited in both cell lines (Figure 2G). The correlation between miR-138$5 \mathrm{p}$ and TRPM2-AS expression was further validated in clinical samples. As a result, a modest but evident negative correlation was identified between miR-138-5p and TRPM2-AS (Figure 2H).

\section{miR-138-5p targeted EGFR to suppress the progression of NSCLC}

Next, miR-138-5p targeting of EGFR was studied. The relative protein expression of EGFR in the NSCLC specimens was significantly higher than that in the adjacent normal tissues (Figure $3 A$ ). Moreover, EGFR mRNA expression was also higher in NSCLC cell lines, especially NCI-H1299 and A549 cells, than in HBE cells (Figure 3B). EGFR was predicted as a potential target of miR-138$5 \mathrm{p}$ in TargetScan. In NCI-H1299 and A549 cells treated with miR-138-5p mimic, mRNA expression of EGFR was significantly inhibited (Figure 3C). Dual luciferase reporter assay validated that EGFR was a target for miR-138-5p (Figure 3D,E). Furthermore, pcDNA-EGFR was shown to 

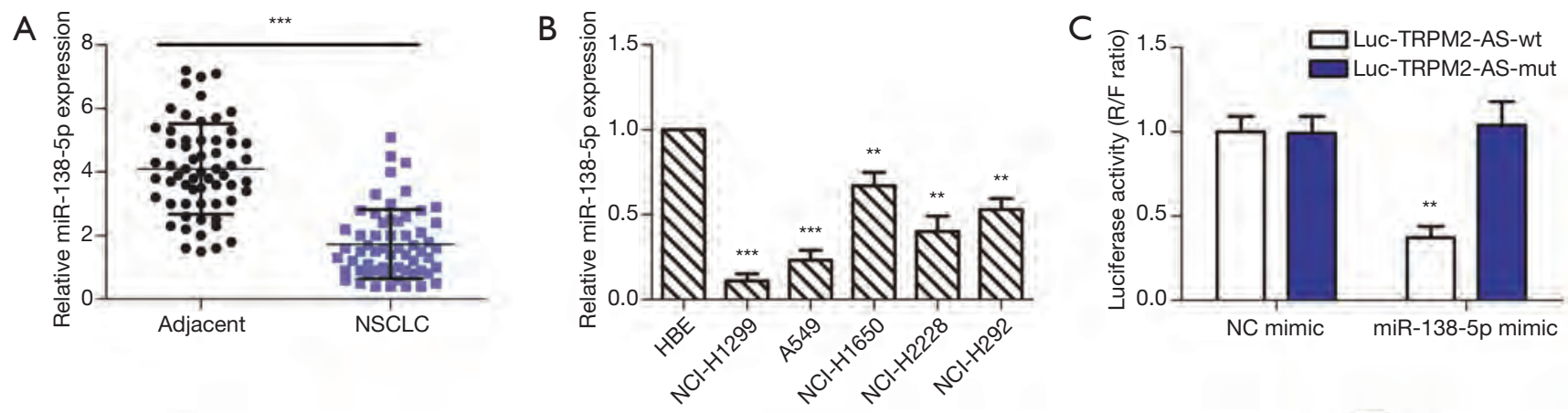

D
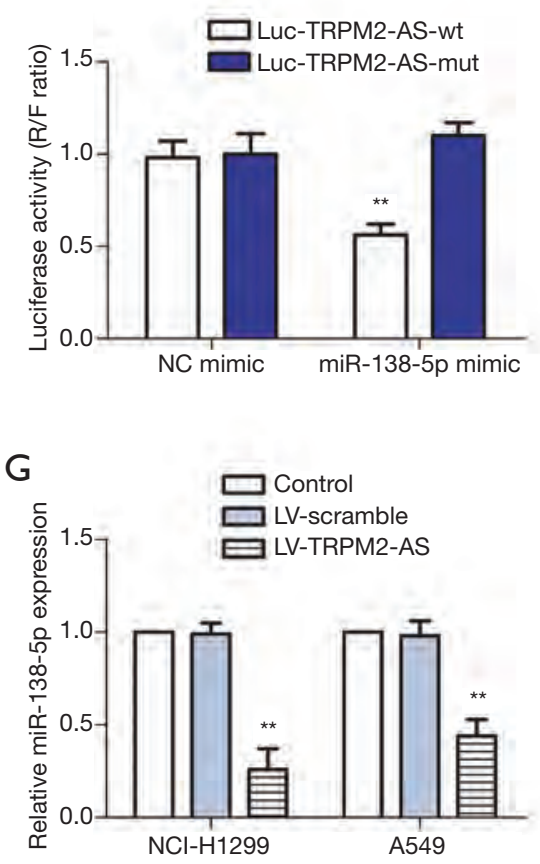

$\mathrm{E}$

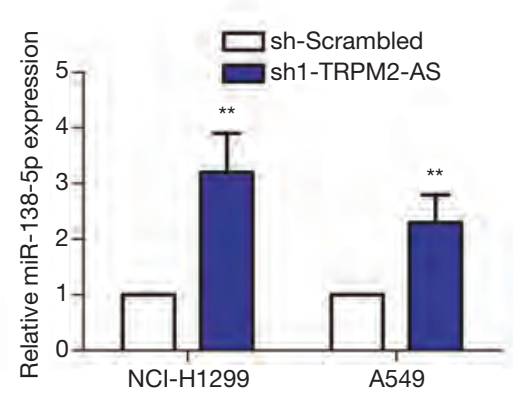

$\mathrm{H}$

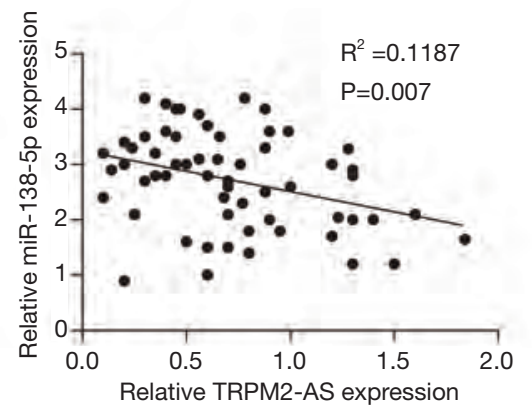

Figure 2 TRPM2-AS is targeted by miR-138-5p. (A) miR-138-5p expression in NSCLC and adjacent tissues from 60 patients was analyzed by paired $t$-test. (B) miR-138-5p expression in HBE cells and several NSCLC cell lines. Targeting of TRPM2-AS by miR-138-5p was verified with luciferase assay in NCI-H1299 (C) and A549 (D) cells. (E) miR-138-5p expression in TRPM2-AS-silenced NCI-H1299 and A549 cells. Expression of TRPM2-AS (F) and miR-138-5p (G) in TRPM2-AS-silenced NCI-H1299 and A549 cells. (H) Pearson's correlation analysis of miR-138-5p and TRPM2-AS in NSCLC tissues from 60 patients. RNA levels were all detected by qRT-PCR. Data are shown as mean $\pm \mathrm{SD}$. ${ }^{* *}, \mathrm{P}<0.01$ and ${ }^{* *}, \mathrm{P}<0.001$ versus control by $\mathrm{t}$-test. NSCLC, non-small cell lung cancer; HBE, human bronchial epithelioid; qRT-PCR, quantitative real-time polymerase chain reaction.

induce overexpression of EGFR in both NCI-H1299 and A549 cells (Figure 3F), while transfection with miR-138-5p mimic and pcDNA-EGFR had the opposite effect, with the inhibition of EGFR protein expression reversed by pcDNAEGFR (Figure 3G,H). The correlation between EGFR protein and TRPM2-AS RNA expression was further validated in clinical samples, and a clear positive correlation was found (Figure 3I). The colony formation and invasion of A549 cells transfected with miR-138-5p mimic or pcDNAEGFR were then tested (Figure 37,K). EGFR showed an opposite effect to miR-138-5p, as the inhibition of colony formation and invasion was reversed by pcDNA-EGFR. These results suggested that miR-138-5p suppressed the progression of NSCLC in vitro by targeting EGFR. 
A
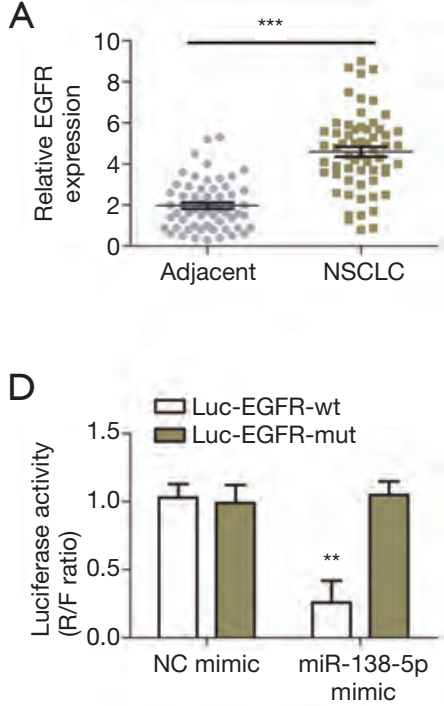

G

$\mathrm{NC}$ mimic + - - - + - -

miR-138-5p mimic - + + - -++-

pCDNA-EGFR $-\quad++-\quad++$

EGFR $-\cdots-m-m$

GAPDH

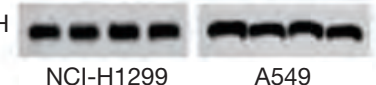

$\mathrm{NCl}-\mathrm{H} 1299$

A549
B

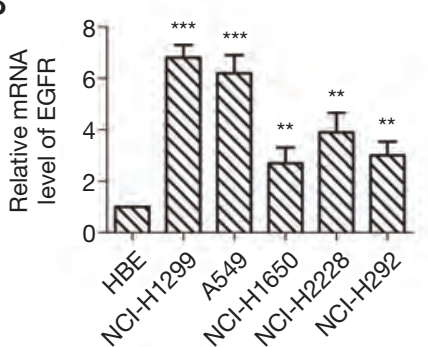

E

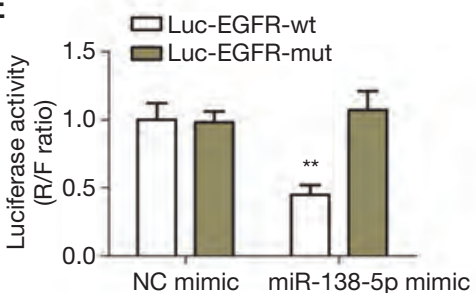

$\mathrm{H}$
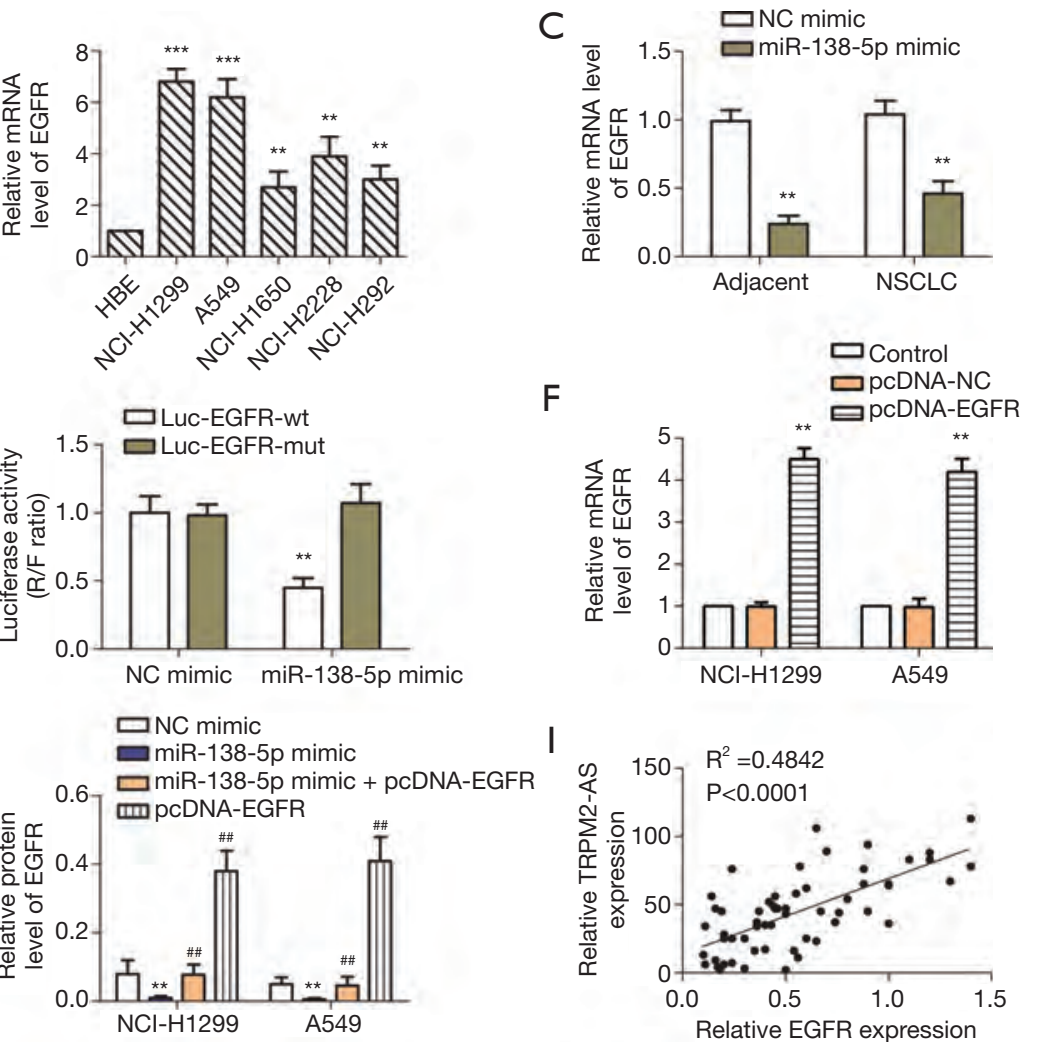

I

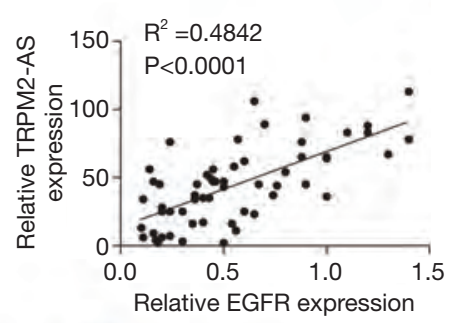

miR-138-5p mimic +

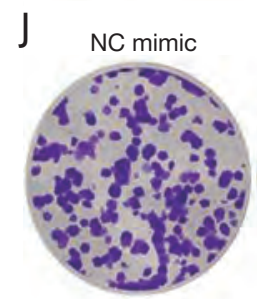

K
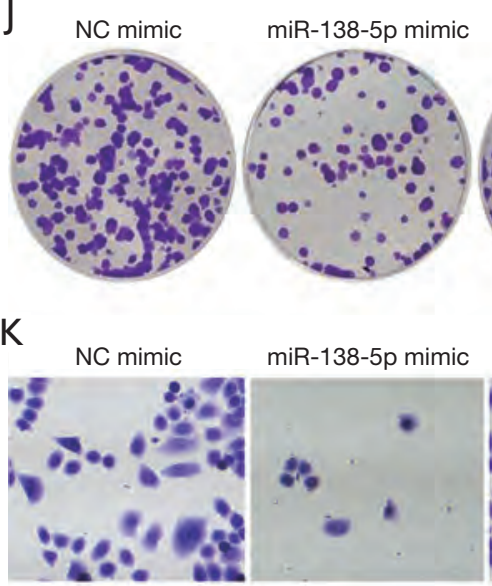

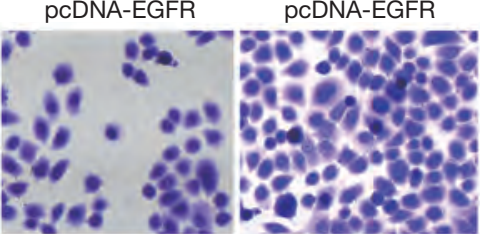

miR-138-5p mimic + PcDNA-EGFR

pcDNA-EGFR

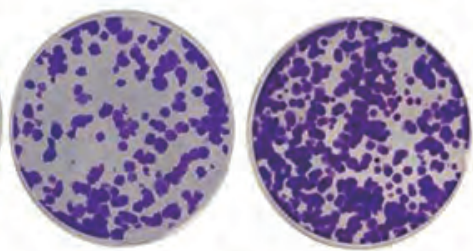
pcDNA-EGFR $\square$ NC mimic

$\square$ miR-138-5p mimic

$\square$ miR-138-5p mimic + pcDNA-EGFR

임D.DNA-EGFR
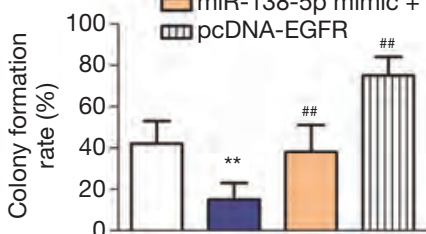

$$
\square \text { NC mimic }
$$

miR-138-5p mimic

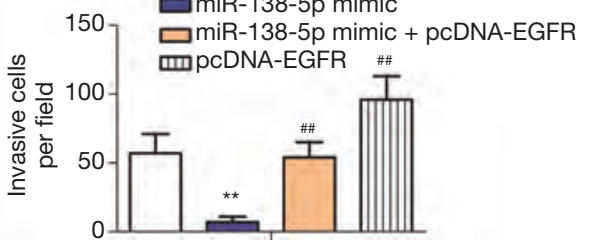

Figure 3 EGFR is targeted by miR-138-5p. (A) Relative protein expression of EGFR in NSCLC and adjacent tissues from 60 patients was analyzed with paired $t$-test. (B) EGFR expression in HBE cells and several NSCLC cell lines. (C) EGFR expression in NCI-H1299 and A549 cells treated with miR138-5p mimic. Targeting of EGFR by miR-138-5p was verified with luciferase assay in NCI-H1299 (D) and A549 (E) cells. (F) RNA expression of EGFR in NCI-H1299 and A549 cells. (G) EGFR protein expression in NCI-H1299 and A549 cells transfected with miR-138-5p mimic and/or pcDNA-EGFR, and $(\mathrm{H})$ the protein level was semi-quantified with Image J. (I) Pearson's correlation analysis of EGFR and TRPM2-AS in NSCLC tissues from 60 patients. Colony formation (stained with crystal violet and directly photographed with a digital camera) (J) and Transwell invasion (stained with crystal violet and observed under 400x scope) (K) assays in NCI-H1299 and A549 cells transfected with miR-138-5p mimic and/or pcDNA-EGFR. RNA and protein levels were detected by qRT$\mathrm{PCR}$ and western blot respectively. Data are shown as mean $\pm \mathrm{SD}$. **, $\mathrm{P}<0.01$ and ${ }^{* * *}, \mathrm{P}<0.001$ versus control and ${ }^{\# \#}, \mathrm{P}<0.01$ versus miR-138$5 \mathrm{p}$ by $t$-test. NSCLC, non-small cell lung cancer; HBE, human bronchial epithelioid; qRT-PCR, quantitative real-time polymerase chain reaction; EGFR, epidermal growth factor receptor. 


\section{miR-138-5p inactivated PI3K/AKT/mTOR signaling in NSCLC}

As co-activation of $\mathrm{PI} 3 \mathrm{~K} / \mathrm{AKT} / \mathrm{mTOR}$ signaling has been reported to promote EGFR-targeted therapy in NSCLC (16), and $\mathrm{miR}-138-5 \mathrm{p}$ is reported to inactivate the PI3K/AKT/ mTOR signaling pathway in lung cancers $(17,18)$, the key regulators of $\mathrm{PI} 3 \mathrm{~K} / \mathrm{AKT} / \mathrm{mTOR}$ signaling were examined in NCI-H1299 and A549 cells transfected with miR-138$5 \mathrm{p}$ mimic or pcDNA-EGFR. In both cell lines, transfection with miR-138-5p mimic clearly inactivated PI3K, AKT, and mTOR, whereas the addition of pcDNA-EGFR reversed these effects (Figure 4A,B). These findings indicated that miR-138-5p suppressed NSCLC, possibly through inhibiting EGFR-mediated PI3K/AKT/mTOR signaling.

\section{Interfering with TRPM2-AS inbibited NSCLC progression in vivo}

As all treatments in this study showed similar outcomes in NCI-H1299 and A549 cells, A549 cells were used in animal experiments to show the possible effects and mechanism of action of TRPM2-AS in vivo. Mice injected with cells transfected with TRPM2-AS shRNA yielded a smaller tumor size (Figure 5A). The tumor volume at day 30 was lower in mice injected with sh-TRPM2-AS-transfected cells, with a significant difference observed from day 20 (Figure 5B). The RNA expression of EGFR was reduced and $\mathrm{miR}-138-5 \mathrm{p}$ expression was increased in the xenograft tumors (Figure 5C). The protein expressions of EGFR and Ki67 were investigated with IHC; apoptotic cells were detected with TUNEL assay (Figure 5D). Both EGFRpositive cells (Figure 5E) and Ki67-positive cells (Figure 5F) were significantly reduced in sh-TRPM2-AS-transfected cells. However, the percent of apoptotic cells in the tumor tissues of mice injected with sh-TRPM2-AS-transfected cells were markedly enhanced (Figure 5G). These findings supported the idea that TRPM2-AS promoted progression of NSCLC in vivo, possibly by targeting EGFR and miR$138-5$ p, and regulating proliferation and apoptosis.

\section{Discussion}

The prognosis of NSCLC, which is one of the most common malignancies, remains poor (9). For patients with metastatic NSCLC, EGFR-targeted therapy can effectively reduce the burden of symptoms and improve overall survival and quality of life (19). Recently, the third- generation EGFR-TKI osimertinib has been shown to significantly improve the survival of patients with EGFR mutations (20). However, as EGFR mutations frequently occur, metastatic NSCLC remains incurable (20). In the present study, we showed that TRPM2-AS sponging of miR-138-5p is a crucial way in which EGFR expression is regulated. Silencing of TRPM2-AS reduced the level of EGFR, inhibited tumor growth, and promoted apoptosis of NSCLC in vitro and in vivo.

TRPM2-AS has been described as an oncogene and has been put forward as a potential novel biomarker and therapeutic target for various cancers, including hepatocellular carcinoma and prostate cancer $(21,22)$. Knockdown of TRPM2-AS has been shown to promote apoptosis in an NSCLC cell line in vitro, partly through the up-regulation of SHC1 (9), and to promote sensitivity to cisplatin by activating the p53-p66shc pathway (5). TRPM2-AS acts as a sponge for miRNAs, which was shown to be its mechanism of action. Currently, confirmed targets for TRPM2-AS include miR-612 and miR-140-3p (6,23), through which TRPM2-AS can promote apoptosis or reduced radioresistance. In the current research, TRPM2AS was estimated to sponge miR-138-5p in multiple sites, many of them were highly possible. One of the predicted miR-138-5p target sites in TRPM2-AS sequence was further validated in NSCLC cell lines in this study. Our findings highlighted the importance of TRPM2-AS/miR138-5p targeting in the pathogenesis of NSCLC.

MiR-138-5p has been broadly implicated as a suppressor in the regulation of drug resistance (24), EMT, proliferation, and metastasis in lung cancer (14). In other tumors, miR138-5p also has involvement in similar processes, such as stemness of oral squamous cell carcinoma (25), autophagy in pancreatic cancer (26), and angiogenesis in glioma (12). Many upstream lncRNAs and circRNAs of miR138-5p have been identified, such as TRPM2-AS (7), circFOXO3 (10), circ_002136 (12), and lncH19 (27). In all of these studies, sponged miR138-5p promoted tumor progression. Downstream of miR-138-5p was also complicated as it targets multiple important regulators; for instance, $G$ protein-coupled receptor GPR124 (13), zinc finger E-boxbinding homeobox protein ZEB2 (14), and members of the autophagy-related PI3K/AKT/mTOR signaling pathway (17). By targeting these molecules, up-regulated miR-138-5p has been shown to inhibit tumor progression and reduce therapeutic resistance and metastasis. The mechanism by which miR-138-5p inhibits tumor progression depends on the expression profile of the target genes. TRPM2-AS and 
A

\begin{tabular}{|rcccc|}
\hline NC mimic & + & - & - & - \\
miR-138-5p mimic & - & + & + & - \\
pcDNA-EGFR & - & - & + & + \\
\hline
\end{tabular}
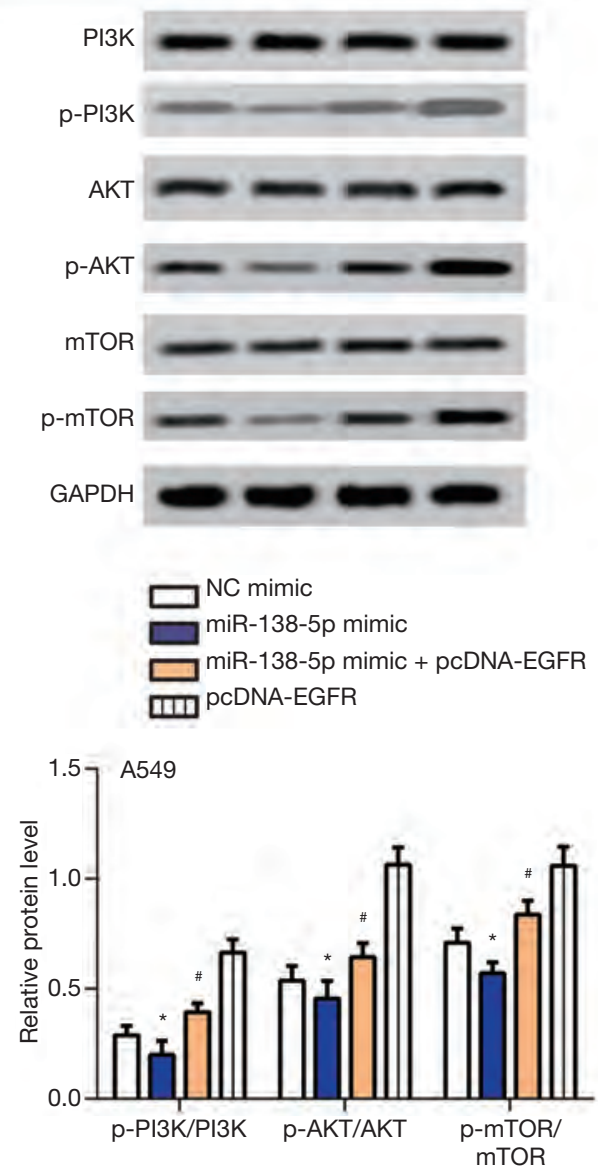

B

\begin{tabular}{|rllll|}
\hline NC mimic & + & - & - & - \\
miR-138-5p mimic & - & + & + & - \\
pcDNA-EGFR & - & - & + & + \\
\hline
\end{tabular}

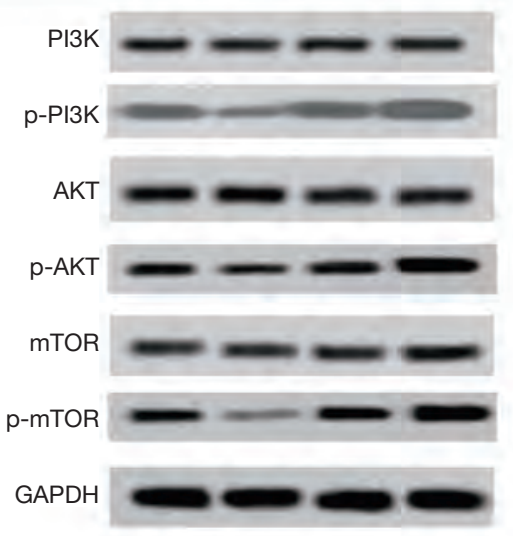

$\square$ NC mimic

$\square$ miR-138-5p mimic

$\square$ miR-138-5p mimic + pcDNA-EGFR

ㅍII] pcDNA-EGFR

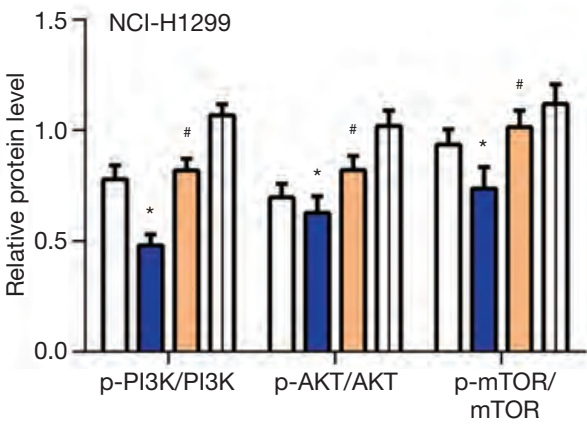

Figure $4 \mathrm{PI}$ K/AKT/mTOR was involved in miR-138-5p/EGFR interaction. (A) Protein expression levels of PI3K, AKT, mTOR, and their phosphorylated forms in NCI-H1299 cells transfected with miR-138-5p mimic and/or pcDNA-EGFR. (B) Protein expression levels of PI3K, AKT, mTOR, and their phosphorylated forms in A549 cells transfected with miR-138-5p mimic and/or pcDNA-EGFR. Protein expression was detected by western blot and analyzed with Image J. Data are shown as mean $\pm \mathrm{SD} .{ }^{*}, \mathrm{P}<0.01 \mathrm{NC}$ mimic and ${ }^{\#}, \mathrm{P}<0.01$ versus miR-138-5p mimic by $t$-test. EGFR, epidermal growth factor receptor.

EGFR are generally elevated in NSCLC tissues, while miR$138-5 \mathrm{p}$ is inhibited $(9,13)$. In this study, we also showed that the expression levels of TRPM2-AS and EGFR were upregulated and that of miR-138-5p was reduced in NSCLC tissues. A positive correlation was observed between TRPM2-AS and EGFR, while TRPM2-AS and miR138$5 \mathrm{p}$ were negatively correlated. The coefficient of association $\left(\mathrm{R}^{2}\right)$ between TTRPM2-AS and miR138-5p was 0.119, which could mainly be attributable to errors introduced by limited miR-138-5p expression. Nevertheless, the probability was evident. Silencing of TRPM2-AS inhibited proliferation, invasion, and metastasis while promoting apoptosis in NSCLC cell lines and in xenograft tumors. Our findings suggest that TRPM2-AS sponging of miR$138-5 \mathrm{p}$ is an important regulatory mechanism of EGFR expression and tumor progression in NSCLC.

Heterogeneity in advanced NSCLC has become more complex over the past decade. While the introduction of EGFR-TKIs has improved the prognosis of NSCLC patients, most patients develop resistance after a year of treatment, which can take the form of mutations of EGFR (on-target drug resistance) and changes in other related signaling pathways (off-target drug resistance) (28). Aberrant activation of PI3K/AKT/mTOR is a hallmark of 
A

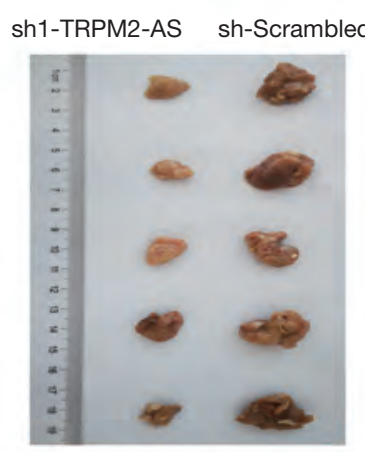

D
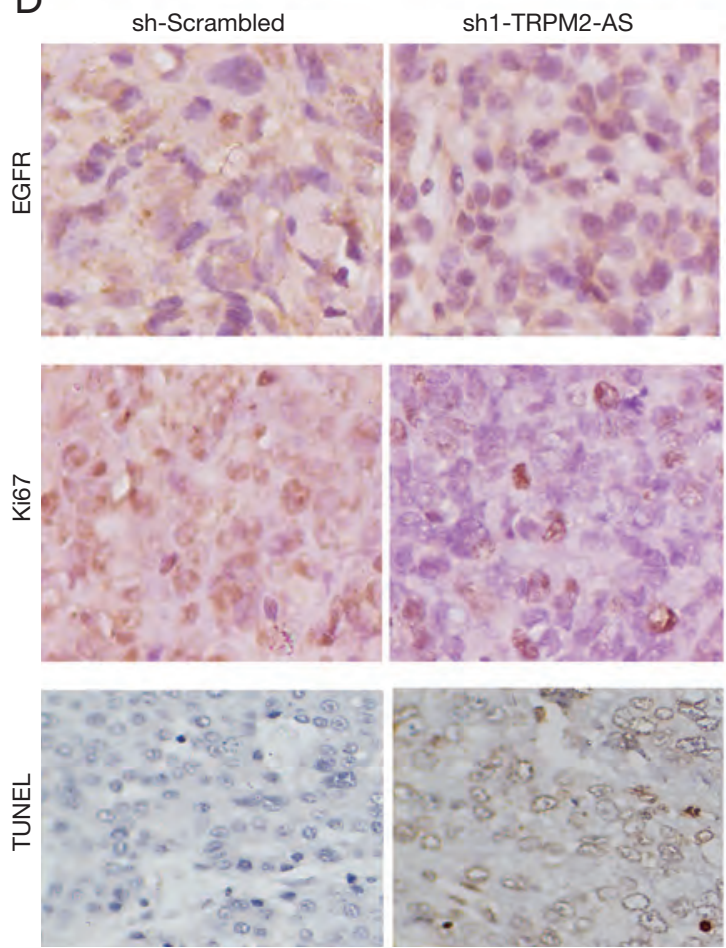

B

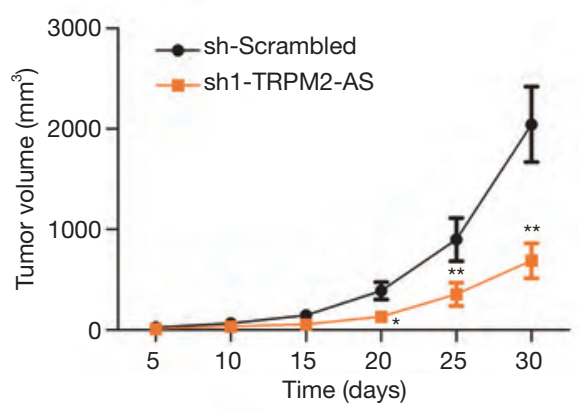

$\mathrm{E}$
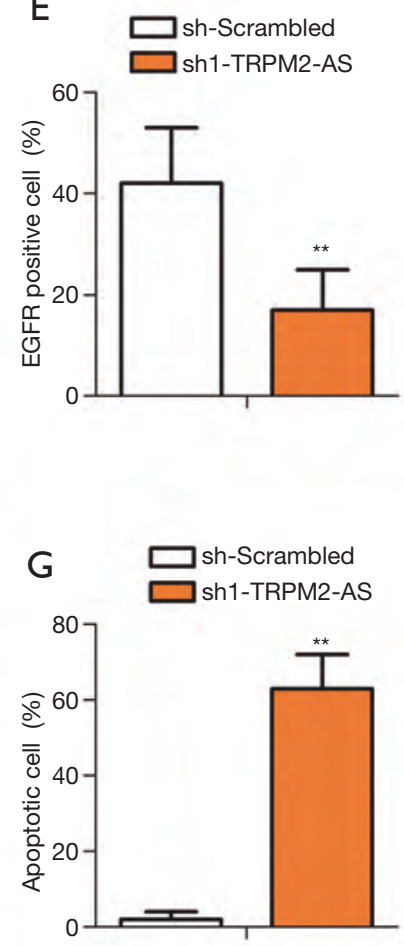
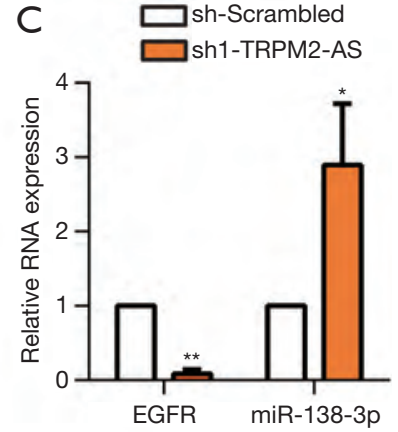

$\mathrm{F}$
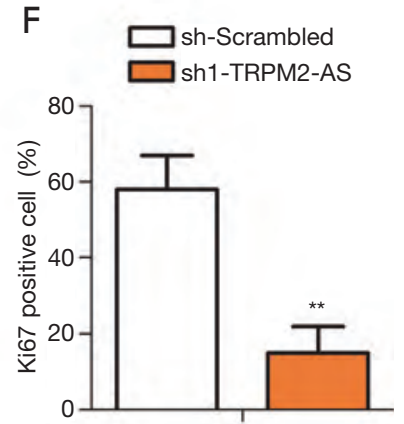

Figure 5 Silencing of TRPM2-AS inhibited NSCLC progression in vivo. After injection with transfected A549 cells, the mice were observed every 5 days and sacrificed on day 30. (A) The tumors were harvested on day 30. (B) The tumor volume was measured and analyzed with oneway analysis of variance. (C) Relative TRPM2-AS and miR-138-5p expression in xenograft tumors was tested by qRT-PCR. (D) Expression levels of EGFR, Ki67, and TUNEL in the xenograft tumors were detected with immunohistochemistry under 200x scope (stained with diaminobenzidine). (E) Relative EGFR expression in the xenograft tumors. (F) Relative miR-138-5p expression in the xenograft tumors was tested by qRT-PCR. (G) Cell apoptosis in the xenograft tumors was tested with TUNEL assay. The staining was analyzed with Image Pro Plus. Data are shown as mean $\pm \mathrm{SD}$. ${ }^{*}, \mathrm{P}<0.05,{ }^{* *}, \mathrm{P}<0.01$ versus control $t$-test or one-way ANOVA. NSCLC, non-small cell lung cancer; qRT-PCR, quantitative real-time polymerase chain reaction; EGFR, epidermal growth factor receptor; ANOVA, analysis of variance.

lung cancer, especially drug-resistant NSCLC (29). PI3K/ $\mathrm{AKT} / \mathrm{mTOR}$ has been reported to be inactivated by miR138-3p and TRPM2-AS (16-18). In the current study, $\mathrm{PI} 3 \mathrm{~K} / \mathrm{AKT} / \mathrm{mTOR}$ was found to be inactivated in NSCLC cells treated with miR-138-5p mimic; however, this effect was reversed by pcDNA-EGFR. Supplementation of
miR-138-5p was also expected to be effective for patients with mutant EGFR. Consequently, both miR-138-5p and TRPM2-AS have been implicated in drug resistance of NSCLC $(5,13)$, which could be a result of their ability to regulate EGFR expression. These findings indicate that TRPM2-AS/miR-138-5p targeted therapy might help 
to overcome both on-target and off-target resistance in therapy for advanced NSCLC.

This study has some limitations. First, the expression levels of TRPM2-AS, miR-138-5p, and EGFR varied from patient to patient. EGFR was clearly not the only target for TRPM2-AS/miR138-5p in NSCLC, and many other up-stream and down-stream molecules for TRPM2-AS, miR138-5p, and EGFR have been identified in multiple tumors. Further investigation is needed to characterize the specific value of TRPM2-AS/miR-138-5p/EGFR feedback.

In conclusion, TRPM2-AS promoted cell proliferation, migration, and invasion in vitro and exacerbated xenograft tumors in vivo through increasing the levels of EGFR via sponging miR-138-3p. Therefore, lncRNA TRPM2-AS sponging of miR-138-5p may be vital in the pathogenesis of NSCLC. The targeting of TRPM2-AS may hold potential as an effective therapeutic strategy for overcoming both ontarget and off-target resistance in the treatment of advanced NSCLC.

\section{Acknowledgments}

Funding: This study was supported by the Henan Province Science and Technology Tackling Project (182102310485).

\section{Footnote}

Reporting Checklist: The authors have completed the ARRIVE reporting checklist. Available at http://dx.doi. org/10.21037/atm-20-6331

Data Sharing Statement: Available at http://dx.doi. org/10.21037/atm-20-6331

Conflicts of Interest: All authors have completed the ICMJE uniform disclosure form (available at http://dx.doi. org/10.21037/atm-20-6331). The authors have no conflicts of interest to declare.

Ethical Statement: The authors are accountable for all aspects of the work in ensuring that questions related to the accuracy or integrity of any part of the work are appropriately investigated and resolved. The study was conducted in accordance with the Declaration of Helsinki (as revised in 2013). The study was approved by Ethics Committee of Henan Provincial Chest Hospital (No. 2018-53). Written informed consent was obtained from all participants. All animal experiments were approved by Henan Provincial Chest Hospital (No. HHSXKYY-2019-019). The animal experiments in this study were performed in strict accordance with the Chinese National Guidelines (GB/T 35892-20181) and the Guide for the Care and Use of Laboratory Animals, 8th edition, published by the National Research Council (US) Committee.

Open Access Statement: This is an Open Access article distributed in accordance with the Creative Commons Attribution-NonCommercial-NoDerivs 4.0 International License (CC BY-NC-ND 4.0), which permits the noncommercial replication and distribution of the article with the strict proviso that no changes or edits are made and the original work is properly cited (including links to both the formal publication through the relevant DOI and the license). See: https://creativecommons.org/licenses/by-nc-nd/4.0/.

\section{References}

1. Global Burden of Disease Cancer Collaboration, Fitzmaurice C, Abate D, et al. Global, Regional, and National Cancer Incidence, Mortality, Years of Life Lost, Years Lived With Disability, and Disability-Adjusted LifeYears for 29 Cancer Groups, 1990 to 2017: A Systematic Analysis for the Global Burden of Disease Study. JAMA Oncol 2019;5:1749-68.

2. Rampinelli C, Minotti M. Improving CT screening for lung cancer with a highly predictive risk model. Ann Transl Med 2018;6:128.

3. Tanzawa $S$, Ishihara $M$, Haruyama $T$, et al. Which is better, EGFR-TKI mono or combination for non-small cell lung cancer with mutated EGFR? Transl Cancer Res 2019;8:2223-9.

4. Meador CB, Hata AN. Acquired resistance to targeted therapies in NSCLC: Updates and evolving insights. Pharmacol Ther 2020:107522.

5. Ma LY, Xie XW, Ma L, et al. Downregulated long noncoding RNA TRPM2-AS inhibits cisplatin resistance of non-small cell lung cancer cells via activation of p53-p66she pathway. Eur Rev Med Pharmacol Sci 2017;21:2626-34.

6. $\mathrm{Hu} \mathrm{J}, \mathrm{Xu} \mathrm{L}, \mathrm{Shou} \mathrm{T}$, et al. Systematic analysis identifies three-lncRNA signature as a potentially prognostic biomarker for lung squamous cell carcinoma using bioinformatics strategy. Transl Lung Cancer Res 2019;8:614-35.

7. Huang B, Chang C, Wang BL, et al. ELK1-induced upregulation of IncRNA TRPM2-AS promotes tumor 
progression in gastric cancer by regulating miR-195/ HMGA1 axis. J Cell Biochem 2019;120:16921-33.

8. Orfanelli U, Jachetti E, Chiacchiera F, et al. Antisense transcription at the TRPM2 locus as a novel prognostic marker and therapeutic target in prostate cancer. Oncogene 2015;34:2094-102.

9. Huang C, Qin Y, Liu H, et al. Downregulation of a novel long noncoding RNA TRPM2-AS promotes apoptosis in non-small cell lung cancer. Tumour Biol 2017;39:1010428317691191.

10. Li X, Huang TL, Zhang GD, et al. LncRNA ANRIL impacts the progress of osteoarthritis via regulating proliferation and apoptosis of osteoarthritis synoviocytes. Eur Rev Med Pharmacol Sci 2019;23:9729-37.

11. Gonzalez Dos Anjos L, de Almeida BC, Gomes de Almeida T, et al. Could miRNA Signatures be Useful for Predicting Uterine Sarcoma and Carcinosarcoma Prognosis and Treatment? Cancers (Basel) 2018;10:315.

12. He Z, Ruan X, Liu X, et al. FUS/circ_002136/miR$138-5 \mathrm{p} / \mathrm{SOX} 13$ feedback loop regulates angiogenesis in Glioma. J Exp Clin Cancer Res 2019;38:65.

13. Gao Y, Fan X, Li W, et al. miR-138-5p reverses gefitinib resistance in non-small cell lung cancer cells via negatively regulating $\mathrm{G}$ protein-coupled receptor 124 . Biochem Biophys Res Commun 2014;446:179-86.

14. Zhu D, Gu L, Li Z, et al. MiR-138-5p suppresses lung adenocarcinoma cell epithelial-mesenchymal transition, proliferation and metastasis by targeting ZEB2. Pathol Res Pract 2019;215:861-72.

15. Tang X, Jiang J, Zhu J, et al. HOXA4-regulated miR-138 suppresses proliferation and gefitinib resistance in non-small cell lung cancer. Mol Genet Genomics 2019;294:85-93.

16. Zhang J, Qu Z, Yao H, et al. An effective drug sensitizing agent increases gefitinib treatment by down regulating $\mathrm{PI} 3 \mathrm{~K} / \mathrm{Akt} / \mathrm{m}$ TOR pathway and up regulating autophagy in non-small cell lung cancer. Biomed Pharmacother 2019;118:109169.

17. Si F, Sun J, Wang C. MicroRNA-138 suppresses cell proliferation in laryngeal squamous cell carcinoma via inhibiting EZH2 and PI3K/AKT signaling. Exp Ther Med 2017;14:1967-74.

Cite this article as: Cui D, Feng Y, Shi K, Zhang H, Qian R. Long non-coding RNA TRPM2-AS sponges microRNA-138-5p to activate epidermal growth factor receptor and PI3K/AKT signaling in non-small cell lung cancer. Ann Transl Med 2020;8(20):1313. doi: 10.21037/atm-20-6331
18. Ye Z, Fang B, Pan J, et al. miR-138 suppresses the proliferation, metastasis and autophagy of non-small cell lung cancer by targeting Sirt1. Oncol Rep 2017;37:3244-52.

19. Arbour KC, Riely GJ. Systemic Therapy for Locally Advanced and Metastatic Non-Small Cell Lung Cancer: A Review. JAMA 2019;322:764-74.

20. Ramalingam SS, Vansteenkiste J, Planchard D, et al. Overall Survival with Osimertinib in Untreated, EGFR-Mutated Advanced NSCLC. N Engl J Med 2020;382:41-50.

21. Mouraviev V, Lee B, Patel V, et al. Clinical prospects of long noncoding RNAs as novel biomarkers and therapeutic targets in prostate cancer. Prostate Cancer Prostatic Dis 2016;19:14-20.

22. Xu C, Huang Q, Zhang $\mathrm{C}$, et al. Long non-coding RNA TRPM2-AS as a potential biomarker for hepatocellular carcinoma. Ir J Med Sci 2018;187:621-8.

23. Sun T, Song Y, Yu H, et al. Identification of lncRNA TRPM2-AS/miR-140-3p/PYCR1 axis's proliferates and anti-apoptotic effect on breast cancer using co-expression network analysis. Cancer Biol Ther 2019;20:760-73.

24. Yu F, Pang G, Zhao G. ANRIL acts as onco-lncRNA by regulation of microRNA-24/c-Myc, MEK/ERK and Wnt/ $\beta$-catenin pathway in retinoblastoma. Int $\mathrm{J}$ Biol Macromol 2019;128:583-92.

25. Zhuang Z, Xie N, Hu J, et al. Interplay between DeltaNp63 and miR-138-5p regulates growth, metastasis and stemness of oral squamous cell carcinoma. Oncotarget 2017;8:21954-73.

26. Tian S, Guo X, Yu C, et al. miR-138-5p suppresses autophagy in pancreatic cancer by targeting SIRT1. Oncotarget 2017;8:11071-82.

27. Ou L, Wang D, Zhang H, et al. Decreased Expression of miR-138-5p by lncRNA H19 in Cervical Cancer Promotes Tumor Proliferation. Oncol Res 2018;26:401-10.

28. Liu WJ, Du Y, Wen R, et al. Drug resistance to targeted therapeutic strategies in non-small cell lung cancer. Pharmacol Ther 2020;206:107438.

29. Tan AC. Targeting the PI3K/Akt/mTOR pathway in non-small cell lung cancer (NSCLC). Thorac Cancer 2020;11:511-8.

(English Language Editor: J. Reynolds) 
Table S1 Predicted targets of TRPM2-AS for miR-138-5p in cm.jefferson.edu/rna22/. (miR name: my_mir_noheader_provided_1; transcript name: NC_000021.9_c44425563 44414590 Homo sapiens chromosome 21, GRCh38.p13 Primary Assembly)

\begin{tabular}{|c|c|c|c|}
\hline $\begin{array}{l}\text { Leftmost position of } \\
\text { predicted target site }\end{array}$ & Folding energy (in -Kcal/mol) & $\begin{array}{l}\text { Heteroduplex (5'-3' for TRPM2-A and } \\
\text { 3'-5' for miR-138-5p) }\end{array}$ & $P$ value \\
\hline 22 & -25.80 & $\begin{array}{l}\text { TGGCCATGCAGGTCG-AACACCAGCT } \\
:||||||||:|||||| 1|1| \\
\text { GCCGG-AC--TAAGTGTTGTGGTCGA }\end{array}$ & $7.31 \mathrm{E}-2$ \\
\hline 195 & -16.40 & $\begin{array}{l}\text { GGGCCGGCGAAAC-TCAGCAGCC } \\
|+||+||+|+|| \\
\text { GCCGGACTAAGTGTTGTGGTCGA }\end{array}$ & $1.42 \mathrm{E}-1$ \\
\hline 528 & -13.40 & $\begin{array}{l}\text { GAGCC-CCCCAC-CC-CCAGCT } \\
|+|+||+||+|| \\
\text { GCCGGACTAAGTGTTGTGGTCGA }\end{array}$ & 2.19E-2 \\
\hline 996 & -15.50 & $\begin{array}{l}\text { AAGCCAGA-GGATGGAGCCAGCA } \\
\qquad \begin{array}{l}|||| \mid \\
\text { GCCGGACTAAGTGTTGTGGTCGA }\end{array}\end{array}$ & 3.37E-2 \\
\hline 1263 & -15.00 & $\begin{array}{l}\text { TGGTGGATGGT-GGATGCCCCAGCA } \\
:|+: \quad||:| \quad:|+| 1 \mid+ \\
\text { GCCG--GACTAAGTGTTGTGGTCGA }\end{array}$ & $1.61 \mathrm{E}-2$ \\
\hline 1811 & -13.50 & $\begin{array}{l}\text { AGGCCCCGACCTCGGACCCACCTGCT } \\
\qquad \begin{array}{l}|||||||||||||| \\
\text { GCCGG-ACT-AAGTGT-TGTGGTCGA }\end{array}\end{array}$ & 1.83E-1 \\
\hline 3708 & -12.00 & 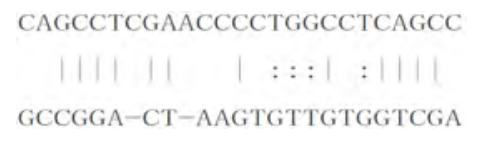 & $2.84 \mathrm{E}-3$ \\
\hline 4328 & -12.00 & $\begin{array}{l}\text { AAGC--GATTCTCCTGCCTCAGCC } \\
\qquad|||+|||:|:| 1|| \\
\text { GCCGGACTAAGTG-TTGTGGTCGA }\end{array}$ & $3.42 \mathrm{E}-3$ \\
\hline 4613 & -16.30 & $\begin{array}{l}\text { TGGCCAGTGGTGGAAGCTGAGCCACCT } \\
:|||| \quad||:|\quad:| \quad:|||| \mid \\
\text { GCCGG-ACTA-AGTGTTGTGGTCGA }\end{array}$ & $1.21 \mathrm{E}-2$ \\
\hline 4750 & -17.60 & $\begin{array}{l}\text { TGAGCCCTTAACACA-TGCCAGCC } \\
:|+||\quad|+||::|+||| \\
\text { GC-CGGACTAAGTGTTGTGGTCGA }\end{array}$ & $2.11 \mathrm{E}-1$ \\
\hline 5050 & -13.80 & $\begin{array}{l}\text { CCTGGAGACCAGCGACCCCAGCC } \\
\qquad||:|:|||||||\end{array}$ & $2.57 \mathrm{E}-3$ \\
\hline 5088 & -16.80 & $\begin{array}{l}\text { GCCGGACTAAGTGTTGTGGTCGA } \\
\text { AGGCCAGG--AACTAACAGCAGTT } \\
|+|||:|||+||+|: \mid \\
\text { GCCGGACTAAGTG-TTGTGGTCGA }\end{array}$ & $2.57 \mathrm{E}-3$ \\
\hline 5598 & -16.90 & $\begin{array}{l}\text { CCACCATCGTCACCACCACCAGCA } \\
||+|||+||+| \mid \\
\text { GCCGGACTAAGTG-TTGTGGTCGA }\end{array}$ & $1.84 \mathrm{E}-4$ \\
\hline 5604 & -18.30 & $\begin{array}{l}\text { TCGTCACCACCACCAGCACCAGCA } \\
|:|+|+||+||| \mid \\
\text { GCCGGACTAAGTG-TTGTGGTCGA }\end{array}$ & $1.84 \mathrm{E}-4$ \\
\hline 6062 & -20.30 & $\begin{array}{l}\text { GGGTGATGAT-AAAAGCACCAGCC } \\
|1: \quad|+|| \quad|:|+|1| 1 \mid \\
\text { GCCG-GACTAAGTGTTGTGGTCGA }\end{array}$ & 3.85E-1 \\
\hline 7115 & -15.50 & $\begin{array}{l}\text { CCTCCTCGTTC-TTCTCCAGCT } \\
\qquad \begin{array}{l}|||+| \\
\text { GCCGGACTAAGTGTTGTGGTCGA }\end{array}\end{array}$ & $1.59 \mathrm{E}-1$ \\
\hline 7217 & -16.10 & 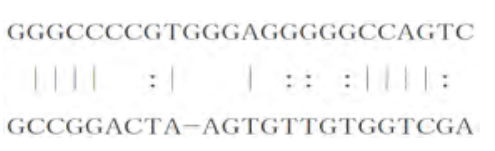 & $3.85 \mathrm{E}-1$ \\
\hline 7255 & -20.20 & $\begin{array}{l}\text { GAGCC-CATCGCA-CACCTGCC } \\
\qquad|||+|:|+||||| \mid \\
\text { GCCGGACTAAGTGTTGTGGTCGA }\end{array}$ & 2.03E-2 \\
\hline 10383 & -16.10 & $\begin{array}{l}\text { GTGC-AAATCCACAAAACCAGCA } \\
\qquad||+||+|||+|+|| \mid \\
\text { GCCGGACTAAGTGTTGTGGTCGA }\end{array}$ & $1.08 \mathrm{E}-3$ \\
\hline 10814 & -14.90 & $\begin{array}{l}\text { CCCCCT-TTTC-TTCCACCAGCC } \\
\qquad|||||:||||||| \\
\text { GCCGGACTAAGTGTTGTGGTCGA }\end{array}$ & $1.26 \mathrm{E}-2$ \\
\hline
\end{tabular}




\section{$5^{\prime}$...CGUUCAAUUCAUCCUCACCAGCA... \\ ||||| ||||||| \\ 3' GCCGGACUAAGUGUU-GUGGUCGA}

Figure S1 Targeting of epidermal growth factor receptor (EGFR) by miR-139-5p predicted with TargetScan 7.2.

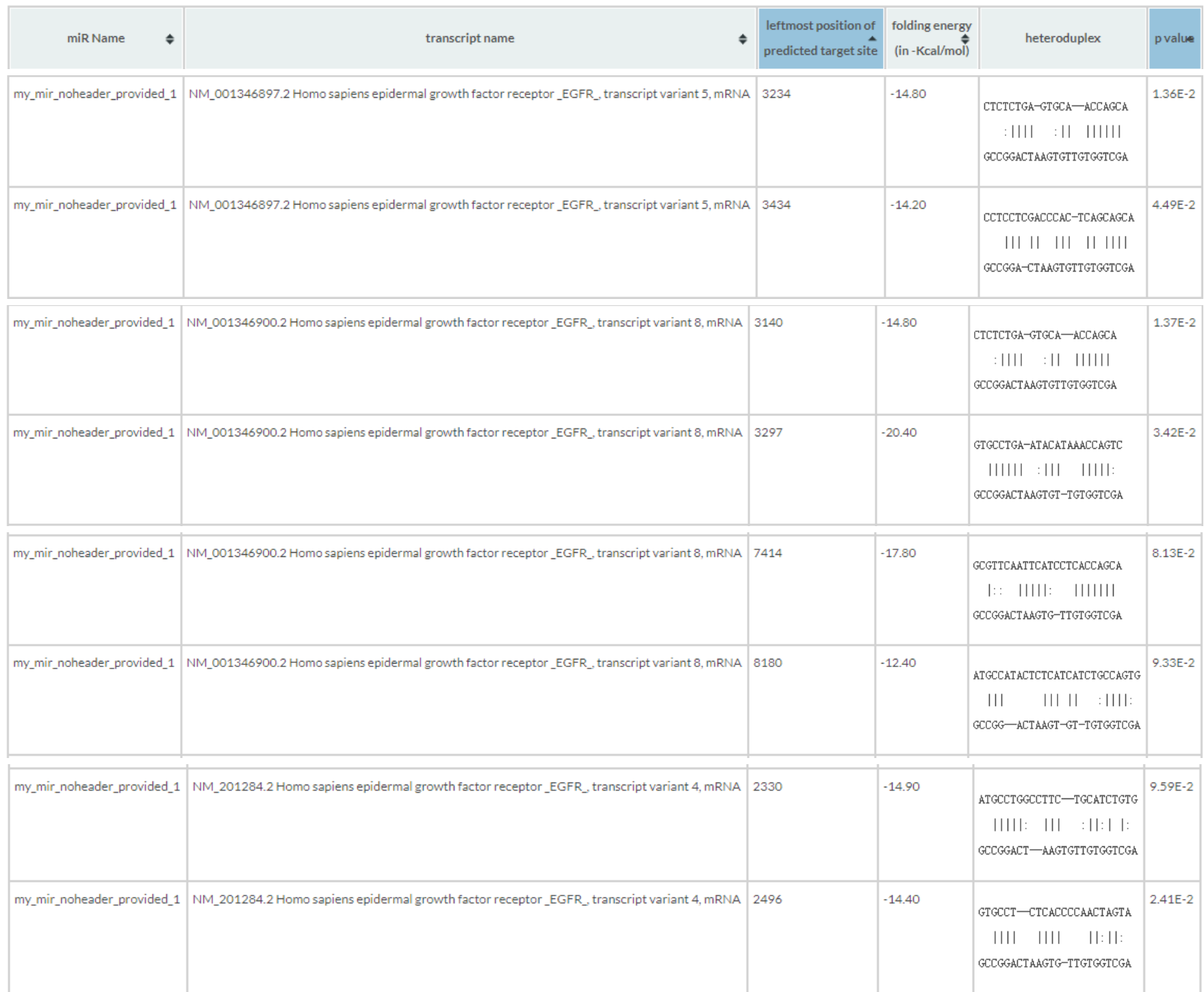

\begin{tabular}{|c|c|c|c|c|c|}
\hline miR Name $\quad \Rightarrow$ & transcript name & $\begin{array}{l}\text { leftmost position of } \\
\text { predicted target site }\end{array}$ & $\begin{array}{l}\text { folding energy } \\
\text { (in-Kcal/mol) }\end{array}$ & heteroduplex & pvalue \\
\hline my_mir_noheader_provided_1 & NM_001346898.2 Homo sapiens epidermal growth factor receptor_EGFR_transcript variant 6, mRNA & 3369 & -14.80 & $\begin{array}{l}\text { CTCTCTGA-GTGCA-ACCAGCA } \\
\text { :IIII : :I IIIIII } \\
\text { GCCGGCTAAGTGTGTGGTCGA }\end{array}$ & $1.36 \mathrm{E}-2$ \\
\hline my_mir_noheader_provided_1 & NM_001346898.2 Homo sapiens epidermal growth factor receptor_EGFR_transcript variant 6, mRNA & 3569 & -14.20 & $\begin{array}{l}\text { CCTCCTCGACCCAC-TCAGCCAGCA } \\
\text { III || ||| || ||| } \\
\text { GCCGGA-CTAAGTGTTGTGGCGA }\end{array}$ & 4.49E-2 \\
\hline
\end{tabular}

\begin{tabular}{|c|c|c|c|c|c|}
\hline my_mir_noheader_provided_1 & NM_005228.5 Homo sapiens epidermal growth factor receptor_EGFR_transcript variant 1, mRNA 33 & 3369 & -14.80 & $\begin{array}{l}\text { CTCTCTGA-GTGCA-ACCAGCA } \\
\text { :|III : || ||IIII } \\
\text { GCCGGACTAAGTGTTGTGGTCGA }\end{array}$ & 1.37E-2 \\
\hline my_mir_noheader_provided_1 1 & NM_005228.5 Homo sapiens epidermal growth factor receptor_EGFR_transcript variant 1 , mRNA 3 & 3526 & -20.40 & $\begin{array}{l}\text { GTGCCTGA-ATACATAAACCAGTC } \\
\text { |IIIII : III IIII: } \\
\text { GCCGGACTAAGTGT-TGTGGTCGA }\end{array}$ & $3.42 \mathrm{E}-2$ \\
\hline my_mir_noheader_provided_1 1 & NM_001346899.1 Homo sapiens epidermal growth factor receptor_EGFR_transcript variant 7, mRNA & 3230 & -14.80 & $\begin{array}{l}\text { CTCTCTGA-GTGCA-ACCAGCA } \\
: \| I I \mid \text { :| IIIIII } \\
\text { GCCGGACTAAGTGTTGTGGTCGA }\end{array}$ & $1.36 \mathrm{E}-2$ \\
\hline my_mir_noheader_provided_1 & NM_001346899.1 Homo sapiens epidermal growth factor receptor_EGFR_transcript variant 7, mRNA & 3387 & -20.40 & $\begin{array}{l}\text { GTGCCTGA-ATACATAAACCAGTC } \\
|||||| \text { : II IIII: } \\
\text { GCCGGACTAGGTGT-TGTGGTGA }\end{array}$ & $3.41 \mathrm{E}-2$ \\
\hline
\end{tabular}

Figure S2 Representative targeting of mutant epidermal growth factor receptor (EGFR) by miR-138-5p. 


\begin{tabular}{|c|c|}
\hline TRPM2-AS-wt & $\begin{array}{c}\text { 5'-CCACCATCGTCACCACCACCAGCA-3' }|||||| \\
\text { miR-138-5p mimic } \\
\text { TRPM2-AS-mut }\end{array}$ \\
3'-GCCGGACUAAGUG-UUGUGGUCGA-5' \\
\hline
\end{tabular}

Figure S3 Luciferase report vectors of the TRPM2-AS and miR-138-5p mimics used.

\begin{tabular}{|c|c|}
\hline EGFR-wt & $\begin{array}{c}\text { 5'-CGUUCAAUUCAUCCUCACCAGCA-1||||| } \\
\text { miR-138-5p mimic } \\
\text { EGFR-mut }\end{array}$ \\
3'-CCGGACUAAGUGUU-GUGGUCGA-5' \\
5'-CGUUCAUAAGUUCCUGUGGUCGA-3' \\
\hline
\end{tabular}

Figure S4 Luciferase report vectors of the epidermal growth factor receptor (EGFR) and miR-138-5p mimics used. 